\title{
Tidewater calving
}

\author{
C.J. VAN DER VeEN \\ Byrd Polar Research Center, The Ohio State University, Columbus, Ohio 43210, U.S.A.
}

\begin{abstract}
Data from Columbia Glacier are used to identify processes that control calving from a temperate tidewater glacier and to re-evaluate models that have been proposed to describe iceberg calving. Since 1981, Columbia Glacier has been retreating rapidly, with an almost seven-fold increase in calving rate from the mid1970s to 1993. At the same time, the speed of the glacier increased almost as much, so that the actual rate of retreat increased more slowly. According to the commonly accepted model, the calving rate is linearly related to the water depth at the terminus, with retreat of the glacier snout into deeper water, leading to larger calving rates and accelerated retreat. The Columbia Glacier data show that the calving rate is not simply linked to observed quantities such as water depth or stretching rate near the terminus. During the retreat, the thickness at the terminus appears to be linearly correlated with the water depth; at the terminus, the thickness in excess of flotation remained at about $50 \mathrm{~m}$. This suggests that retreat may be initiated when the terminal thickness becomes too small, with the rate of retreat controlled by the rate at which the snout is thinning and by the basal slope. The implication is that the rapid retreat of Columbia Glacier (and other comparable tidewater glaciers) is not the result of an increase in calving as the glacier retreated into deeper water. Instead, the retreat was initiated and maintained by thinning of the glacier. For Columbia Glacier, the continued thinning is probably associated with the increase in glacier speed and retreat may be expected to continue as long as these large speeds are maintained. It is not clear what mechanism may be responsible for the speed-up but the most likely candidate is a change in basal conditions or subglacial drainage. Consequently, the behavior of tidewater glaciers may be controlled by processes acting at the glacier bed rather than by what happens at the glacier terminus.
\end{abstract}

\section{INTRODUCTION}

Calving from glacier termini is an important, yet poorly understood mechanism for ice loss, permitting much larger volumes of ice to be lost from a glacier than would be possible through melting. It has been suggested (Hodge, 1979; Meier, 1979) that calving glaciers are inherently unstable, with no stable response to a long-term massbalance deficit (Clarke, 1987). During the last deglaciation, large quantities of icebergs were produced by the Laurentide ice sheet on at least six occasions (Heinrich, 1988; Broecker, 1994) and increased calving may have been crucial to the rapid disintegration of the great Pleistocene ice sheets (e.g. Thomas, 1977; Pollard, 1984; Warren and Hulton, 1990). Indeed, once initiated, the rate of retreat of the calving front can be impressive. For example, during the second half of 1991, the terminus of Columbia Glacier, Alaska, U.S.A., retreated at a rate of almost $4 \mathrm{~km} \mathrm{a}^{-1}$ (Krimmel, 1992; see also Fig. 1), discharging vast quantities of icebergs into Prince William Sound, and posing serious hazards to the major shipping routes used by supertankers transporting oil from the terminal of the Trans-Alaskan pipeline at Valdez (Dickson, 1978). Obtaining a better understanding of the calving process is crucial when addressing the possibility of past or future rapid changes in those parts of the cryosphere that are potentially prone to changes in climate.
Tidewater glaciers flow towards the sea, terminating in an ice cliff from which icebergs are discharged. This process may be termed tidewater calving to make a distinction with calving from floating termini. In most cases, the lower reaches of tidewater glaciers are confined laterally as the ice passes through a relatively narrow fjord on its way to the open sea. At the mouths of these fjords, or in places where the fjord widens or joins another larger fjord, end moraines are often found, suggesting the most advanced position of the glacier terminus. In polar regions, the terminus may be floating, as is the case for the lower $10 \mathrm{~km}$ of Jakobshavns Isbræ, West Greenland (Echelmeyer and others, 1991). It could be argued that such glaciers are essentially ice shelves that have formed in narrow embayments and, as such, may display different behavior from glaciers whose terminus is grounded. Reeh (1994) suggested that, for floating termini, a search for a general calving relation may be illusory, because other factors that may influence the rate of calving, such as discharge of ice across the grounding line and geometry of the fjord, are specific for each individual glacier. For temperate tidewater glaciers, such as those found in Alaska, the terminus is usually grounded up to the calving front, although parts of the terminal region may incidentally become afloat. In this study, only tidewater glaciers whose terminus is (mostly) grounded are considered. 
The calving rate (unit: $\mathrm{m} \mathrm{a}^{-1}$ ) is defined as the volume of icebergs discharged per unit time and per unit vertical area of the terminus (Paterson, 1994, p.376). Equivalently, the calving rate represents the speed at which the terminus retreats due to iceberg production. This retreat is countered by the forward movement of the snout caused by ice flow. The net rate of change in terminus position is thus equal to the ice velocity at the terminus minus the calving rate.

A number of theoretical studies has been conducted to derive expressions for the rate of calving. The majority of these apply to floating glaciers and ice shelves (e.g. Reeh, 1968; Holdsworth, 1978). A model for calving from the terminus of a grounded glacier was developed by Hughes (1989, 1992) and Hughes and Nakagawa (1989). Hughes argued that bending shear is the mechanism that controls calving from grounded ice walls. At the front of the glacier, the sea-water pressure is insufficient to balance the weight-induced lithostatic stress and a longitudinal tensile stress develops. This stress increases from the bottom to the top of the ice front so that it acts eccentrically, resulting in bending of the glacier terminus. By considering forces and couples acting on the snout of the glacier, Hughes (1992) derived the following expression for the calving rate

$$
U_{\mathrm{c}}=\frac{3 \rho g H^{4} \theta}{\eta C^{2}}\left(1-\frac{\rho_{\mathrm{w}}(H-D)}{\rho H}\right)
$$

where $\eta$ is the viscoplastic viscosity of creep, $\rho$ and $\rho_{\mathrm{w}}$ are the density of ice and sea water, respectively, $H$ is the ice thickness at the terminus and $D$ denotes the water depth at the terminus. Bending creep in shear bands up to a distance $C$ from the terminus causes the terminal slab to incline at an angle $\theta$ from the vertical. The calving ratio, $C / H$, is essentially unknown and the theory proposed by Hughes (1992) does not give an expression from which the calving ratio can be estimated. While Hughes (1992) explored several parameterizations for the calving ratio that are consistent with data from 12 Alaskan glaciers given in Brown and others (1982), the results are ambiguous and inconclusive due to the uncertainty in the original data. Additionally, the bending-shear mechanism requires a substantial ice height above the flotation thickness. During its retreat, the terminal thickness of Columbia Glacier approached the flotation thickness. This means that Hughes' model cannot be applied to the retreat phase of Columbia Glacier or other tidewater glaciers whose terminus approaches flotation (personal communication from T.J. Hughes, 1996).

A different approach to the problem of iceberg calving is to use observations to determine empirically how the rate of calving depends on measured variables, such as water depth or height of the terminal freeboard. Brown and others (1982) conducted a statistical analysis of data from 12 Alaskan tidewater glaciers and concluded that the annual width-averaged calving rate, $U_{\mathrm{c}}$ (in $\mathrm{km} \mathrm{a}^{-1}$ ), is correlated with the water depth, $D$ (in $\mathrm{m}$ ), as

$$
U_{\mathrm{c}}=0.027 D \text {. }
$$

Pelto and Warren (1991), who considered the Alaskan data set with additional data from glaciers in Greenland and Svalbard, derived a somewhat different, but also linear, relationship:

$$
U_{\mathrm{c}}=0.07+0.008 D \text {. }
$$

These relations suggest that the annual-mean rate of calving increases linearly with water depth at the terminus. An almost equally good fit between calving rate and thickness at the terminus exists for the Alaskan glacier data (Brown and others, 1982, table 7). Thus, it is not clear whether ice thickness or water depth should be considered as an independent variable in the calving law, although in most studies the water-depth dependency is adopted, because of the marginally better fit.

It may be noted that, despite the linear relation obtained, Pelto and Warren (1991) argued that this relation cannot be a causal one. The water-depth relation may be necessary but cannot by itself explain observed calving rates. If the water depth at the terminus increases, the rate of iceberg production may increase, but an increase in calving rate need not always be associated with an increase in water depth. On the other hand, while recognizing that the physical processes that determine calving are not yet quantified, Meier (1994) concluded that the linear calving relation should be considered seriously for modeling and prediction.

Seasonal changes in calving rate have been studied by Sikonia (1982), who considered calving rates and ice speeds measured on the center line of Columbia Glacier for the period 24 July 1977-2 September 1980, as determined from repeat aerial photogrammetry. There is no meaningful correlation between the seasonal calving rate and water depth but Sikonia and Post (1980) argued that there is a correlation between calving rate and discharge of water at the bed. Because the actual subglacial drainage is impossible to measure, Sikonia (1982) instead used as proxy the discharge of nearby Knik River. A calving relation that fits these data is

$$
U_{\mathrm{c}}=1.092 \times 10^{6}\left(\frac{K^{0.57}}{H_{\mathrm{b}}^{2.18}}\right)
$$

where $K$ represents the Knik River discharge $\left(\right.$ in $^{3} \mathrm{~s}^{-1}$ ) and $H_{\mathrm{b}}$ is the height above buoyancy, defined as

$$
H_{\mathrm{b}}=H-\frac{\rho_{\mathrm{w}}}{\rho} D \text {. }
$$

While all of these calving relations are based on a best fit to available data, they appear to be contradictory. The annual, width-averaged, calving rate is determined primarily by water depth and appears to be only weakly correlated with the height above buoyancy (Pelto and Warren, 1991, fig. 2). The seasonal center-line calving rate, on the other hand, shows a good correlation with the height above buoyancy and almost no correlation with the water depth. Sikonia (1982) offered three possible explanations, namely (i) one or other of the calving relations is wrong, (ii) some unidentified process averages the seasonal relation (Equation (4)) into the annual relation (Equation (2) or (3)) for time periods of 1 year or longer, or (iii) the linear relations and the seasonal one describe two different calving processes that, as yet, have not been separated. Pelto and Warren (1991) have 
suggested a fourth possibility, namely that the linear relation between calving rate and water depth is a spurious result due to limited data.

A few comments concerning the linear calving relation appear to be appropriate. There are few, if any, theoretical arguments as to why the calving rate should depend linearly on the water depth near the terminus, although water depth features prominently in the theoretical model of Hughes (1992). More importantly, eight of the 12 glaciers considered by Brown and others (1982) are either in steady state or retreating only slowly. Omitting the four rapidly retreating glaciers from the statistical analysis improves the correlation coefficient of the linear fit, $r^{2}$, from 0.91 for the entire data set to 0.98 for the reduced set. This indicates that the linear calving relation is primarily due to the eight glaciers whose termini are close to steady state. Under such steady conditions, many correlations may exist that do not describe the governing processes. In order to validate any calving relation, it should be tested unambiguously against theory and observations, in particular those made on tidewater glaciers during the phase of rapid retreat. However, a comprehensive calving theory has, as yet, not been developed and the only theory available for calving from grounded glaciers contains a number of essentially unknown parameters and may not apply to comparatively thin tidewater glaciers. This means that the linear calving law cannot yet be verified or disproven by theory. Nevertheless, the linear relation (Equation (2) or (3)) can be adopted as a working hypothesis and evaluated against available data, in particular data collected on Columbia Glacier prior to and during its rapid retreat.

Columbia Glacier is one of about 45 glaciers surrounding Prince William Sound on the south coast of Alaska. In 1978, the glacier covered about $1100 \mathrm{~km}^{2}$ and was about $66.6 \mathrm{~km}$ long. The position of the terminus had been stable from at least the late 1700 s until the early 1980s. Because of the imminent possibility of retreat, the U.S.G.S. (Tacoma) initiated a monitoring program on Columbia Glacier in the summer of 1976. Since then, aerial photogrammetry on the lower reaches has been conducted by the U.S.G.S. (Tacoma) about five times per year (Fountain, 1982; Krimmel, 1987, 1992; Krimmel and Vaughn, 1987; personal communication from R. M. Krimmel, 1993), documenting the onset and subsequent course of the rapid retreat that started in 1981. This extensive data set provides simultaneous estimates of glacier retreat and glacier speed from which the calving rate can be inferred. This avoids one of the problems associated with the Alaskan glacier data set used by Brown and others (1982), namely that retreat and ice speed were not always measured in the same year.

The Columbia Glacier data set represents the only documentation of a tidewater glacier just prior to the onset of retreat as well as covering the subsequent collapse of the lower regions. These data offer a unique opportunity to study tidewater calving (among many other processes). In an earlier study, Meier (1994) used these data to test the linear calving relation derived by Brown and others (1982). His conclusion was that the newer Columbia Glacier data, covering the period 1979-93, are consistent with relation (2). However, this view may be challenged.
As noted by Meier (1994), both the annual calving rate and water depth at the terminus increased up to the mid 1980s. After about 1985, the relation between calving rate and water depth becomes more obscured. In fact, Meier's data appear to indicate that the dramatic increase in calving rate since 1990 occurred while the glacier terminus retreated into shallower water (Meier, 1994, fig. 5). When considered separately, a linear relation between calving rate and water depth represents a mediocre fit to the Columbia Glacier data $\left(r^{2}=0.51\right)$. When combined with the Alaskan data, the correlation coefficient for the linear fit is 0.74 . Meier (1994) attributed the decrease in $r^{2}$ to added extra noise from the Columbia Glacier data. Alternatively, it could be argued that the linear-calving relation applies only to the eight Alaskan glaciers that are close to steady state and that the reduction in correlation coefficient is due to adding data points from glaciers that do not obey Equation (2). To a large extent, the ambiguity in the calving data presented by Meier (1994), and the lack of any definite answer against or in favor of the linearcalving relation, may be attributed to the comparative paucity of data points. Meier (1994) considered 14 annual calving rates from Columbia Glacier, one value for each of the years 1979-93. The number of data points can be greatly increased if the available U.S.G.S. data are used to their full extent and the time series of the running-mean calving rate is considered. It may be expected that this procedure better reveals any trends in the data and possible correlations between calving rate and other observed parameters.

\section{COLUMBIA GLACIER GALVING, 1976-93}

Columbia Glacier has been monitored regularly since the summer of 1976 by aerial photogrammetry conducted by the U.S.G.S. (Tacoma) about five times per year. Derived surface elevations and surface speeds have been given by Fountain (1982) and Krimmel (1987, 1992). Digital copies of these data, as well as of more recent measurements, were kindly provided by R. M. Krimmel of the U.S.G.S. (Tacoma). In this study, data from 74 flight intervals, covering the period from 24 July 1976 to 10 July 1993, are considered.

The calving rate is found by taking the difference between the rate of advance of the glacier terminus and the ice speed near the terminus. On each photograph, points along the terminus across the width of the glacier were measured to define the position of the terminus. The average terminus position is defined as the average over the $2.5 \mathrm{~km}$ wide central part of the glacier (Krimmel, 1992). Dividing the change in terminus position by the length of the flight interval yields the rate of change in terminus position, shown in the upper panel of Figure 1. Surface velocities in both horizontal directions are derived from tracking of distinct surface features on successive photographs (Fountain, 1982; Krimmel, 1987, 1992). These photogrammetrically determined velocities do not extend all the way to the glacier terminus. Extrapolation to the terminus of gridded velocities was tried but yielded obviously unrealistic results, so the speed at the terminus is assumed equal to the speed at the seaward boundary of the data. For most flight intervals, 

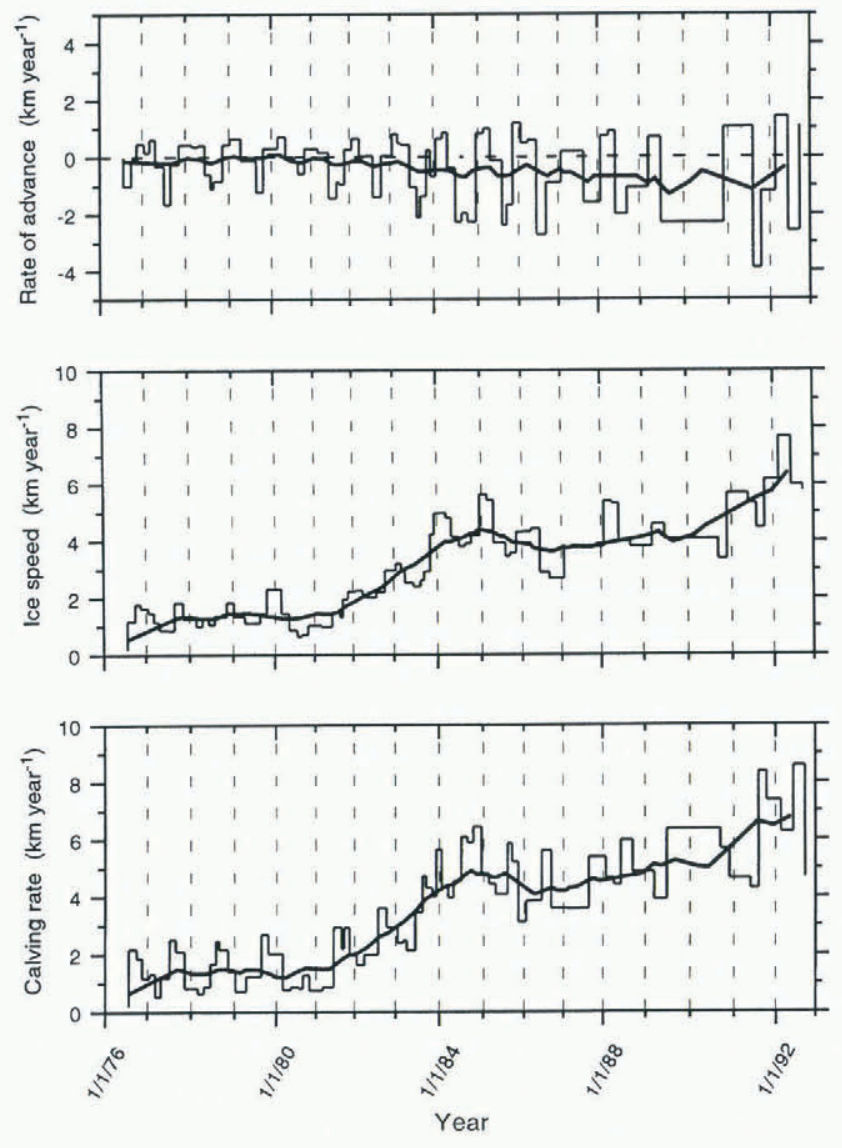

Fig. 1. Rate of terminus advance, ice speed at the terminus and calving rate, for Columbia Glacier, 1976-93. The heavy curves represent the centered 2 year running mean.

the distance between the last velocity determination and the terminus is less than $1 \mathrm{~km}$, so the error thus introduced may not be too severe (Van der Veen, 1995). The ice speed at the terminus, also averaged over the $2.5 \mathrm{~km}$ wide center part, is shown in the second panel of Figure 1. The calving rate (Fig. 1; third panel) is obtained from the difference between the upper two panels.

The terminus exhibits an annual cycle of retreat in late summer, followed by an advance in the spring (Fig. 1; upper panel). Until the winter of 1978-79, the terminus remained grounded on Heather Island, at the seaward end of the fjord, but between 8 November 1978 and 6 January 1979 the ice front retreated from Heather Island and has been unable to re-establish contact since. Near the western margin of the glacier, the position of the ice front did not change much until early 1984, when retreat from the terminal moraine began. In places, the ice front retreated over distances of more than $1500 \mathrm{~m}$ during the summer of 1984 (cf. Meier and others, 1985a). Since then, the terminus has retreated at an increasing rate.

The glacier speed exhibits a clear annual cycle and the power distribution of the velocity shown in the second panel of Figure 1 contains only one significant peak, centered around 1 year (Van der Veen, 1995, fig. 19). In addition, short-term measurements of glacier speed show diurnal and semi-diurnal variations associated with the two main tidal constituents (Walters and Dunlap, 1987) and increased ice flow after heavy rainfall events Krimmel and Vaughn, 1987; Walters and Dunlap,
1987; Meier and others, 1994). Near the terminus, the seasonal velocity reaches a maximum in late fall and early winter, while the minimum occurs during the summer. Meier and others (1985b) proposed that this terminalvelocity pulse is caused by the seasonal retreat of the glacier front. Farther up-glacier, the maximum in velocity occurs in late spring and the minimum in late summer (Krimmel and Vaughn, 1987). Similar seasonal variations in ice velocity have been observed on other glaciers (e.g. Hodge, 1974; Hooke and others, 1983; Iken and others, 1983) and are generally attributed to changes in basal drainage as water input from surface melting increases (Hodge, 1974; Tangborn and others, 1975).

The curve of calving rate (Fig. 1; third panel) closely resembles that of ice speed, mainly because the rate of advance (or retreat) changed much less than did the ice speed. Over the period of consideration, the calving rate increased by almost a factor of 7 , as predicted by the linear relation between $U_{\mathrm{c}}$ and water depth the water depth increased from about 50 to $300 \mathrm{~m}$ ). In fact, comparison between the calving rate and water depth at the terminus (Fig. 2, upper panel) suggests that there is a correlation between these two quantities, with the calving rate increasing as the water depth increases. A similar approximate correlation appears to exist between calving rate and the other quantities shown in Figure 2. However, a quantitative examination of the correlation between calving rate and any of the quantities shown in Figure 2 indicates that $U_{\mathrm{c}}$ is not simply linked to any of these parameters (Fig. 3). While for a number of the relations tested the best fit has a large correlation coefficient $\left(r^{2}>0.8\right.$; Table 1$)$, visual inspection of the curves in Figure 3 indicates that these relations only describe the general trend in a very broad sense, even if only the 2 year running-mean data are considered.

As was to be expected, the seasonal calving rates are much more variable than the 2 year running-mean values (Fig. 3). The seasonal values derive from successive photogrammetry flights and represent averages over periods of 1 to several months. Because calving is not a continuous process and may contain a stochastic component, short-term observations of calving rate are not best suited for understanding the nature of iceberg production. Therefore, the present study focuses on the 2 year runningmean calving rates to eliminate short-term temporal fluctuations that may otherwise confuse the discussion.

The largest uncertainty in the Columbia Glacier data set is associated with the basal elevations. In this study, elevations derived by Rasmussen (1989) are used for the main part of the fjord, while near the terminal moraine elevations derive from direct bathymetric soundings (Brown and others, 1986). These basal elevations may contain an important error and the poor correlation between calving rate and water depth could be attributed to uncertainties in the bed topography. However, this does not appear to be a likely explanation. Figure 4 shows a comparison between inferred water depth calculated using the 2 year running-mean calving rates and the linear-calving relation (2) (using a fixed value for the constant of proportionality) and the bed topography derived by Rasmussen (1989). The linear-calving relation predicts almost constant water depth until early 1980, a rapid increase until late 1984 , followed by a decrease until 

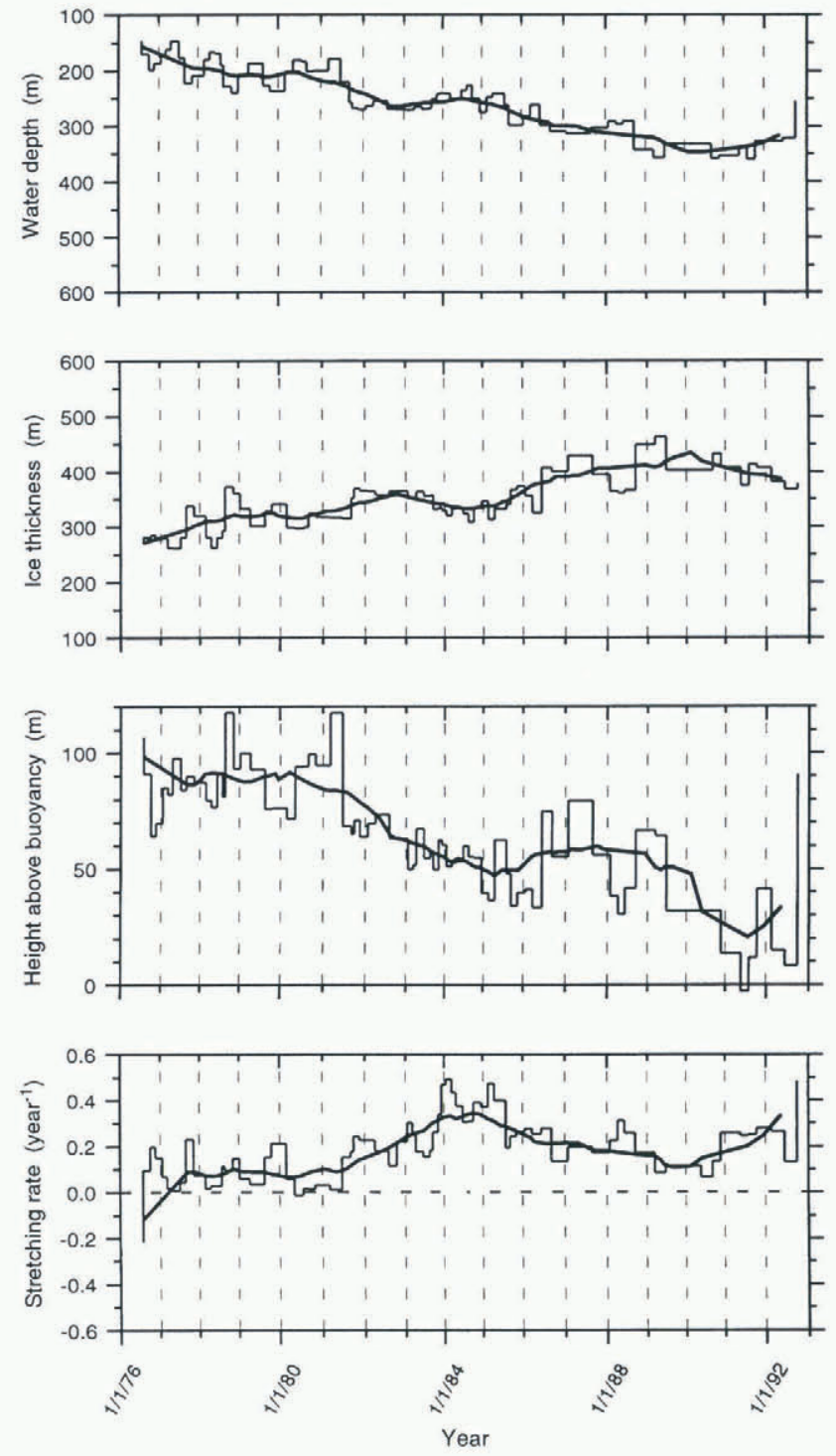

Fig. 2. Water depth, ice thickness and height above buoyancy at the terminus of Columbia Glacier. The lower panel shows the along-flow stretching rate averaged over the lower $6 \mathrm{~km}$ (or less, if fewer data are available) of glacier length. The heavy curves represent the 2 year centered running mean.

early 1986 and finally a gradual deepening in more recent years. This pattern does not correspond to the Rasmussen basal topography and differences are most notable for the late $1970 \mathrm{~s}$ (prior to the rapid retreat) and mid $1980 \mathrm{~s}$ (immediately after the onset of rapid retreat). There is no indication that the basal elevations obtained by Rasmussen are in error by such a large amount that the differences can be explained or that the general trend of the basal topography derived by Rasmussen is in error, and it may be concluded that the uncertainty in basal topography is an unlikely explanation for the lack of correlation between calving rate and water depth.

Although the linear calving relation (2) has been applied to the retreat phase of Columbia Glacier (Rasmussen and Meier, 1982; Meier, 1994) and is generally invoked to explain the observed cycling of tidewater glaciers (e.g. Powell, 1991; Warren, 1992), it should be noted that Meier and Post (1987) raised the
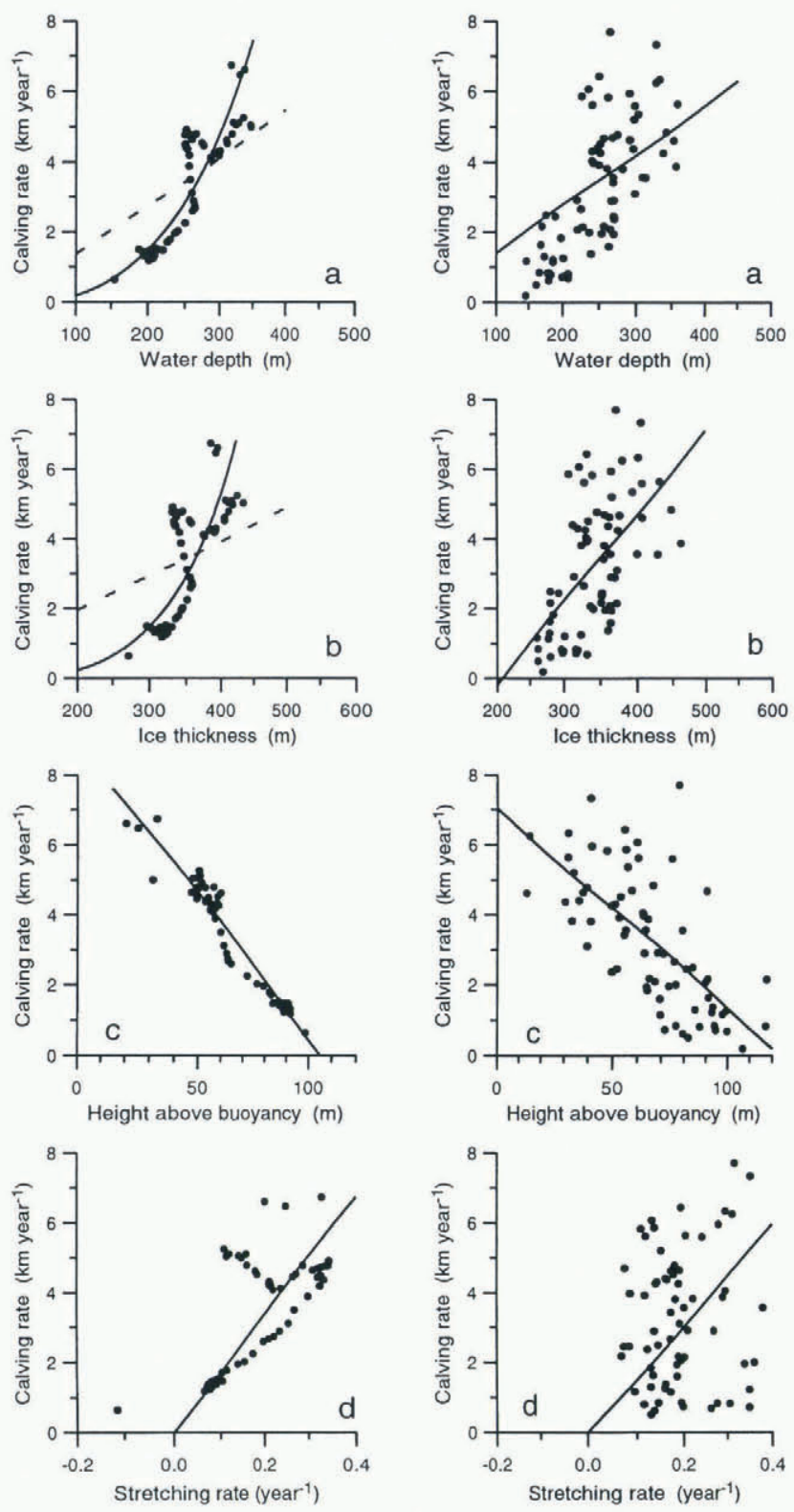

Fig. 3. Relationship belween calving rate and measured quantities, for the seasonal measurements (panels on the right) and the 2 year running-mean values (panels on the left). The full and dashed curves represent some of the best fits to the data given in Table 1.

possibility that the linear-calving law may not be valid when the glacier retreats rapidly because the approach to flotation may become the controlling factor. During the accelerated retreat, another calving relation may become important. It could be conjectured that the Columbia Glacier data support this suggestion. In the graphs shown in Figures 1 and 2, several distinct regimes may be identified. Initially, up to about late 1982, the rate of calving increased as the water depth at the terminus increased and, as the rate of retreat increased, the flow in the terminal region became more tensile. During the second phase, from early 1983 to late 1984, the stretching rate near the terminus continued to increase, maintaining the increase in calving rate despite the decrease in water 
Table 1. Relations fitted to the Columbia Glacier data, 1976-93. $U_{\mathrm{c}}$ is the calving rate $\left(\mathrm{km} \mathrm{a}^{-1}\right), D$ is the water depth at the terminus ( $m$ below sea level), $H$ is the ice thickness at the terminus $(m), H_{\mathrm{b}}$ is the height above buoyancy $(m)$ and $\dot{\varepsilon}_{x x}$ is the stretching rate up-glacier from the terminus $\left(a^{-1}\right)$. The columns labeled "Curve in Figure 3" indicate which of the best-fit relations are shown in Figure 3

\begin{tabular}{|c|c|c|c|c|c|c|}
\hline \multirow[t]{2}{*}{ Relation } & \multicolumn{3}{|c|}{2 year running mean } & \multicolumn{3}{|c|}{ Seasonal values } \\
\hline & Coefficients & $r^{2}$ & $\begin{array}{c}\text { Curve in Fig. } 3 \\
\text { (left panels) }\end{array}$ & Coefficients & $r^{2}$ & $\begin{array}{c}\text { Curve in Fig. } 3 \\
\text { (right panels) }\end{array}$ \\
\hline$U_{\mathrm{c}}=c D$ & $c=0.0137$ & 0.908 & Dash & $c=0.014$ & 0.848 & Full \\
\hline$U_{\mathrm{c}}=c D+d$ & $\begin{array}{l}c=0.031 \\
d=-4.633\end{array}$ & 0.768 & - & $\begin{array}{l}c=50.02 \\
d=-2.915\end{array}$ & 0.493 & - \\
\hline$U_{\mathrm{c}}=c D^{p}$ & $\begin{array}{l}c=3.555 \times 10^{-7} \\
p=2.878\end{array}$ & 0.822 & Full & $\begin{array}{l}c=1.514 \times 10^{-6} \\
p=2.617\end{array}$ & 0.593 & - \\
\hline$U_{c}=c H$ & $c=0.0098$ & 0.861 & Dash & $c=0.00984$ & 0.804 & - \\
\hline$U_{c}=c H+d$ & $\begin{array}{l}c=0.033 \\
d=-8.392\end{array}$ & 0.546 & - & $\begin{array}{l}c=0.0243 \\
d=-5.046\end{array}$ & 0.331 & Full \\
\hline$U_{\mathrm{c}}=c H^{p}$ & $\begin{array}{l}c=1.983 \times 10^{-11} \\
p=4.389\end{array}$ & 0.593 & Full & $\begin{array}{l}c=1.328 \times 10^{-9} \\
p=3.673\end{array}$ & 0.404 & - \\
\hline$U_{\mathrm{c}}=c H_{\mathrm{b}}$ & $c=0.041$ & 0.559 & - & $c=0.038$ & 0.498 & - \\
\hline$U_{\mathrm{c}}=c H_{\mathrm{b}}+d$ & $\begin{array}{l}c=-0.085 \\
d=8.906\end{array}$ & 0.945 & Dash & $\begin{array}{l}c=-0.057 \\
d=7.047\end{array}$ & 0.469 & Full \\
\hline$U_{\mathrm{c}}=c H_{\mathrm{b}}^{p}$ & $\begin{array}{l}c=2528.02 \\
p=-1.637\end{array}$ & 0.812 & - & $\begin{array}{l}c=298.114 \\
p=-1.151\end{array}$ & 0.399 & - \\
\hline$U_{\mathrm{c}}=c \dot{\varepsilon}_{x x}$ & $c=16.843$ & 0.890 & Full & $c=14.912$ & 0.679 & Full \\
\hline$U_{\mathrm{c}}=c \dot{\varepsilon}_{x x}+d$ & $\begin{array}{l}c=12.074 \\
d=1.131\end{array}$ & 0.528 & - & $\begin{array}{l}c=2.547 \\
d=2.777\end{array}$ & 0.011 & - \\
\hline$U_{\mathrm{c}}=c \dot{\varepsilon}_{x x}^{p}$ & $\begin{array}{l}c=13.887 \\
p=0.859\end{array}$ & 0.680 & - & $\begin{array}{l}c=2.958 \\
p=0.064\end{array}$ & 0.001 & - \\
\hline
\end{tabular}

depth at the terminus. Starting in early 1985, the stretching rate decreased for unknown reasons, resulting in a smaller calving rate. As the terminus continued its retreat, the glacier front became grounded in deeper water and, at some point, the water depth once again became the controlling variable for the rate of calving.
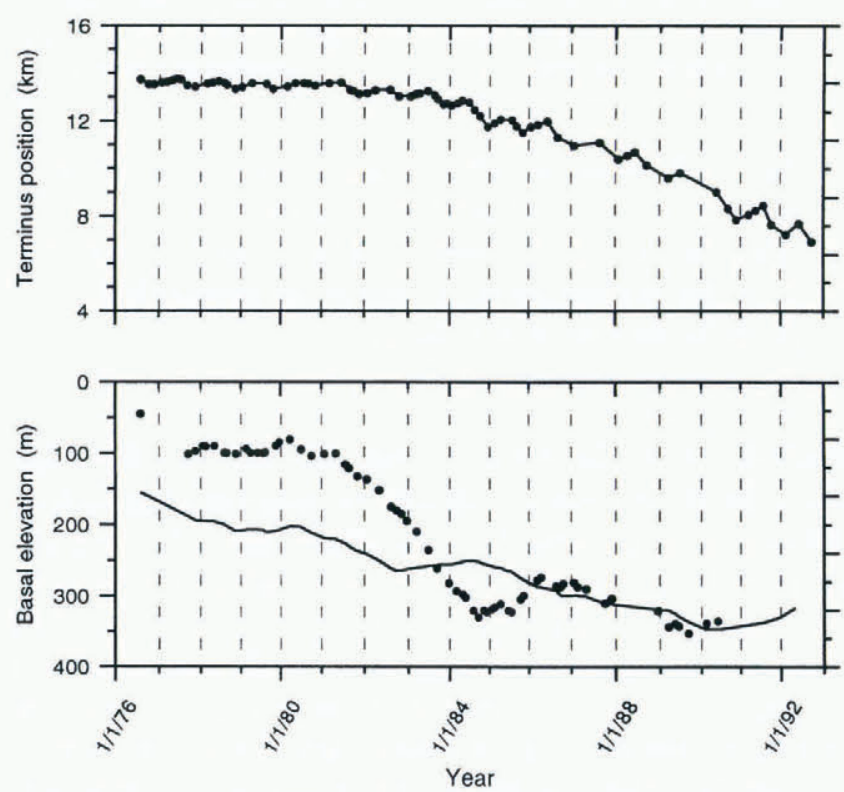

Fig. 4. Upper panel: position of the terminus of Columbia Glacier, 1976-93. Lower panel: water depth inferred from the linear relation (Equation (2)) between calving rate and water depth (black dots). The full curve represents the water depth from Rasmussen (1989).
Thus, it could be that from late 1982 to early 1986 the calving rate was controlled primarily by the stretching rate at the terminus. Before and after this interruption, water depth may have been the controlling parameter. However, without some theoretical description of the processes involved, this scenario remains speculative and not very helpful in understanding the processes controlling iceberg calving. It may be noted, however, that if the water-depth relation does not apply to rapidly retreating glaciers, as suggested by Meier and Post (1987), it is not clear why, after the interruption from 1982 to 1986, water depth would once more become the controlling variable.

Perhaps the most surprising feature of the rapid retreat of Columbia Glacier is that the increase in calving rate was accompanied by an almost equally large increase in glacier speed, resulting in a much smaller rate of terminus retreat than initially predicted. In fact, an excellent correlation between calving rate and ice speed exists, both for the Columbia Glacier data (Fig. 5) and the Alaskan glaciers investigated by Brown and others (1982) (cf. Van der Veen, 1995, fig. 1). From a mathematical point of view, this correlation can be explained by considering the equation from which the calving rate is calculated, namely

$$
U_{\mathrm{c}}=U_{\mathrm{i}}-\frac{\mathrm{d} L}{\mathrm{~d} t}
$$

where $U_{\mathrm{i}}$ represents the ice speed and $L$ is the terminus position. As shown in Figure 1, the ice speed is (much) larger than the rate of change in terminus position, so that, according to Equation $(6), U_{\mathrm{c}}$ may be expected to be closely correlated with $U_{\mathrm{i}}$. From a physical standpoint, 
however, the correlation apparent in Figure 5 is not immediately obvious.

While it could be argued that the Columbia Glacier data support, at least in a general sense, the commonly accepted linear-calving law (as was done by Meier (1994)), the results discussed above indicate that perhaps a re-evaluation of the calving mechanism is warranted. In particular, the issue to be addressed is whether calving can be described by a calving relation of the form in Equation (2) or a more complex variation on it, or whether the calving rate is a secondary parameter, with as controlling variable the position of the terminus, which may be determined by the geometry of the glacier snout. This issue is not merely a matter of semantics but has important consequences for understanding the retreat of Columbia Glacier and other comparable tidewater glaciers.
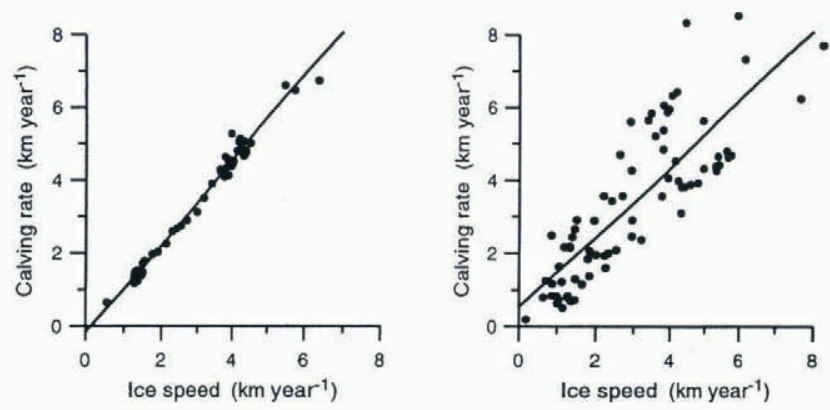

Fig. 5. Correlation between calving rate and ice speed at the terminus for the seasonal measurements (right) and 2 year running-mean values (left). The lines correspond to the best linear fit given in Table 1.

\section{CONTROLS ON GALVING RATE}

The observation that the calving rate is linearly correlated with ice velocity suggests two possible scenarios, namely (i) the same physical process controls ice flow and iceberg production, or (ii) the position of the glacier terminus is controlled by the local geometry. An essential difference exists between these two scenarios. According to the first one, the rapid retreat of Columbia Glacier was caused by an increase in calving rate, perhaps associated with increased water depth at the terminus. The simultaneous increase in ice velocity may have slowed the rate of retreat but calving remained the controlling mechanism and retreat can only be halted if the rate of calving decreases again. In the second scenario, the increase in calving rate is a secondary effect and the retreat of the glacier is due to another process, most likely the increase in glacier speed and associated thinning of the glacier tongue. While the Columbia Glacier data cannot provide a definitive answer in favor of one or the other model, some arguments can be presented to cast reasonable doubt on the first model.

Circumstantial evidence has been used to link calving rate to water depth near the terminus. As argued above, the linear-calving relation derived by Brown and others (1982) may be primarily due to the glaciers whose termini are close to steady state. Under such (semi-)stationary conditions, many correlations may exist that do not describe actual processes but rather reflect the adjustment of the glacier to environmental conditions. The most obvious example of this is the link between ice velocity and integrated surface accumulation. For a steady-state glacier, the ice flux through any cross-section equals the total snowfall accumulated upstream. If the position of the terminus is steady, this means that the calving flux must be equal to the net accumulation integrated over the entire glacier. Thus, an excellent correlation between calving rate and the spatially averaged surface mass balance can be expected. However, this correlation does not describe the causal process for iceberg calving. Similarly, the empirical relation between $U_{\mathrm{c}}$ and $D$ may be incidental, not so much because of the limited number of glaciers considered (as suggested by Pelto and Warren (1991)) but because these glaciers are all close to steady conditions.

Most of the flow of Columbia Glacier is associated with basal sliding which, according to the majority of theories, is controlled by the effective pressure at the glacier bed (e.g. Bindschadler, 1983). The linear correlation between calving rate and glacier speed therefore suggests that, if a calving law exists, the rate of calving should somehow also be related to the effective basal pressure, $P_{\mathrm{e}}$. It is not immediately clear how basal pressure affects calving but it could be envisioned that $P_{\mathrm{e}}$ affects the depth to which surface crevasses penetrate, by raising or lowering the hydraulic grade line in the glacier. Where surface crevasses are able to penetrate deeper, fracture and subsequent detachment from the main body of ice becomes more likely. However, this scenario does not explain why the calving rate should vary with effective basal pressure in a similar way as does the ice speed.

Theoretical models for calving (e.g. Reeh, 1968; Hughes, 1992) are based on the assumption that the lithostatic stress at the terminus is only partially balanced by sea-water pressure. The lithostatic stress is due to the weight of the ice and increases linearly with depth below the upper ice surface (cf. Fig. 6). Taking $z=0$ at sea level and positive upward, and denoting the elevation of the upper surface by $h$, the lithostatic stress is

$$
L(z)=\rho g(h-z) .
$$

Integrated over the total ice thickness, the net lithostatic force per unit width is

$$
F_{\mathrm{L}}=\frac{1}{2} \rho g H^{2} .
$$

Part of this force is balanced by the pressure from sea water on the terminus, which also increases linearly with depth below sea level (the minus sign indicating that this pressure is directed up-glacier):

$$
P_{\mathrm{w}}(z)=-\rho_{\mathrm{w}} g z .
$$

The total hydrostatic force per unit width is then

$$
F_{\mathrm{w}}=\frac{1}{2} \rho_{\mathrm{w}} g D^{2}
$$

Taking the difference between the lithostatic and hydrostatic force, and dividing by the ice thickness to obtain the depth-averaged stress, gives the unbalanced 


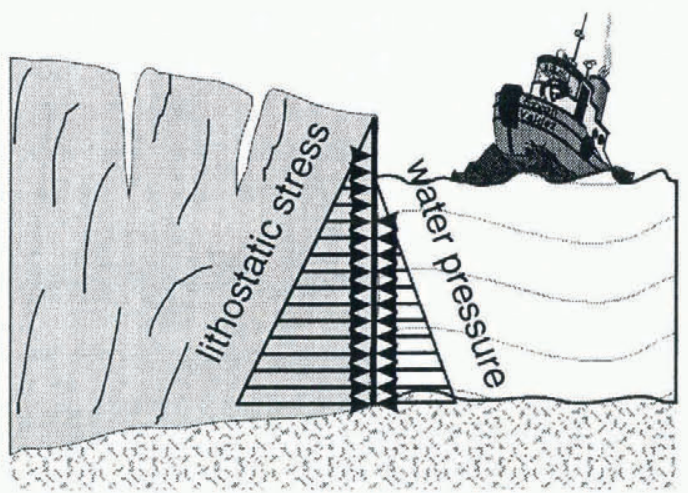

Fig. 6. Illustrating horizontal forces acting at the glacier terminus. The weight-induced lithostatic stress increases linearly with depth below the ice surface and is partially balanced by the water pressure, which increases linearly with depth below the sea surface.

stress at the terminus

$$
\bar{S}_{x}=\frac{1}{2} \rho g H\left[1-\frac{\rho_{\mathrm{w}}}{\rho}\left(\frac{D}{H}\right)^{2}\right] .
$$

Presumably, this stress is responsible for icebergs breaking off.

Without developing a complete theory for stress transmission in the glacier snout, it is not possible to predict how the calving rate depends on the unbalanced stress, but it seems reasonable to assume that calving increases as $\bar{S}_{x}$ becomes larger. As shown in Figure 7, the opposite was true during the retreat of Columbia Glacier. As the glacier retreated into deeper water, the unbalanced lithostatic stress decreased from almost $800 \mathrm{kPa}$ to somewhat less than $400 \mathrm{kPa}$. The fraction of the lithostatic stress not balanced by sea-water pressure (that is, the term between square brackets in Equation (11), shown in the lower panel of Figure 7) decreased from about 55 to $20 \%$ of the depth-averaged lithostatic stress. If, indeed, the force imbalance at the terminus is responsible for calving, it is not clear how a decrease in the unbalanced stress can lead to larger calving rates.

It could be argued that the nature of iceberg calving changed during the rapid retreat of Columbia Glacier and that the search for a calving law that applies to the preretreat conditions as well as to the phase of rapid retreat may be illusory. There is some evidence to support this view. Prior to its rapid retreat, the terminus was grounded on a fairly shallow moraine at the end of the fjord. During calving events, the ice cliff slid from the glacier, shattering as it fell, producing relatively small icebergs. As the terminus retreated into deeper water, calving events were observed during which large icebergs appeared to rise from under water, indicating bottom calving. In recent years, with the glacier terminating in very deep water, the size of the icebergs has increased even more. Some of these large icebergs include serac clusters that seem to float away from the glacier (personal communication from R. M. Krimmel, 1995). The changing character of calving may explain the lack of success in deriving a calving relation that describes the retreat of Columbia Glacier.

While it may not be possible to estimate the calving rate from a theoretical or empirical calving relation, the
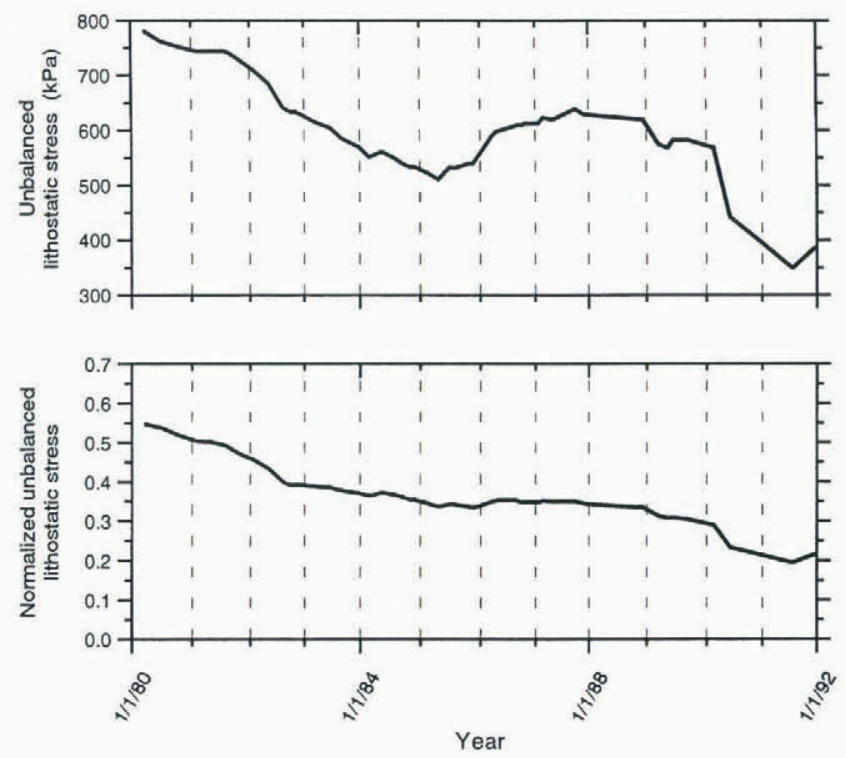

Fig. 7. Difference between lithostatic stress and water pressure during the retreat of Columbia Glacier. The upper panel shows the 2 year running-mean difference in depthaveraged stress, while the lower panel shows this difference normalized with the depth-averaged lithostatic stress.

calving mechanism need not be entirely beyond understanding. Meier and Post (1987) pointed out that the terminus of Columbia Glacier appears to retreat to the point where the effective basal pressure approaches zero. This suggests an entirely different model for iceberg calving, in which the terminus position is determined by the local geometry. During the retreat, the flotation criterion has been reached locally and temporarily at the terminus (Meier and others, 1985a; Meier, 1994), so it could be that the terminus tends to retreat to where the thickness approaches the flotation thickness. Or, in simpler terms, the almost floating part of the snout breaks off, because the ice is too weak to support a floating tongue (Meier and Post, 1987). If so, the thickness at the terminus during the retreat follows from the flotation criterion, and

$$
H=\frac{\rho_{\mathrm{w}}}{\rho} D+H_{0}
$$

where $H_{0}$ represents the minimum thickness above flotation that can be supported by the glacier. Equation (12) represents the minimum thickness at the terminus that can be maintained before the terminus retreats. The actual thickness may be larger if advance is not possible, as is the case if the glacier has reached the terminal moraine at the end of the fjord, beyond which the water depth increases rapidly. During the phase of retreat, thinning may cause the terminal thickness to become less than the minimum thickness given by Equation (12), causing the terminus to retract.

A linear relation between thickness at the terminus, $H$, and water depth, $D$, is supported by the data from Columbia Glacier, at least after the onset of rapid retreat, as shown in Figure 8. The straight line corresponds to Equation (12) with $H_{0}=50 \mathrm{~m}$. The solid dots, representing data points from 1982 onward, closely follow the theoretical prediction. Prior to 1982 , the terminus 


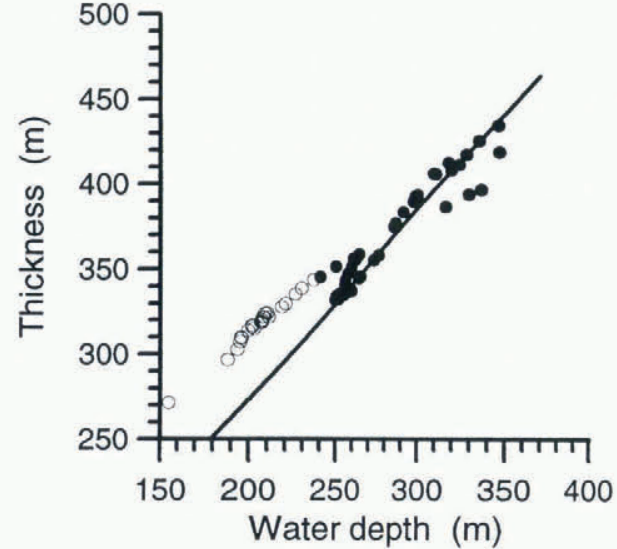

Fig. 8. Correlation between thickness and water depth at the terminus of Columbia Glacier. Open circles indicate measurements prior to 1982 and solid dots data from 1982 onward.

remained grounded on the fjord side of the terminal moraine and the ice thickness appeared to have been larger than the minimum thickness needed to maintain the terminus position. After the glacier thinned sufficiently, rapid retreat was initiated.

According to the calving model proposed here, retreat of the terminus occurs when the thickness becomes less than the minimum thickness. This means that the rate of retreat is controlled by the thinning rate of the ice and by the basal geometry. Approximating the shape of the snout as a wedge, with constant thickness gradient $\alpha=$ $-\partial H / \partial x)$ and constant basal slope, $\beta$, the rate of retreat may be written as

$$
\frac{\partial L}{\partial t}=\frac{1}{G} \frac{\partial H}{\partial t}
$$

where

$$
G=\alpha+\frac{\rho_{w}}{\rho} \beta
$$

represents a geometry factor that can be evaluated from measured surface elevations and basal geometry. However, the uncertainty in basal slope prevents a meaningful calculation of $G$ (the uncertainty in the data becomes more important when gradients are considered, as in this case). Therefore, the procedure is reversed and the present data are used to estimate the geometry factor. Results of this calculation are shown in Figure 9. The rate of retreat (Fig. 9; upper panel) is obtained from the change in terminus position as measured on successive photographs. The thickening rate (Fig. 9; second panel) is estimated from the change in surface elevation measured on the photographs, averaged over the last few kilometers of glacier (cf. Van der Veen, 1995). The geometry factor, $G$ (Fig. 9; lower panel), is the quotient of these two quantities. Prior to the summer of 1983, there is considerable variation in calculated values of $G$ but afterwards the geometry factor remains more constant. The surface slope did not change much during the period considered (Van der Veen, 1995, appendix B), so that variations in $G$ may be associated primarily with the basal topography. The decrease in geometry factor and reduction in variability may be associated with the generally flatter (and perhaps smoother) bed farther into the fjord (Fig. 4). While the uncertainty in the data prohibits a quantitative evaluation, the curves shown in Figure 9 strongly suggest that the rate of glacier retreat is linked to the thinning rate, as predicted by the calving model advanced in this study.

A somewhat different model for the interaction between ice flow and retreat of the glacier has been presented by Meier (1994), based in part on the observation that, generally, high values of stretching rate at the terminus correspond to high rates of calving. As the rate of calving increases, longitudinal stretching becomes larger, leading to thinning of the glacier snout. This thinning leads to decreased effective basal pressure (because the height above buoyancy decreases), which results in faster flow through the dependency of the sliding velocity on effective basal pressure at the bed. The increase in ice velocity slows the rate of retreat, so the interaction between ice flow and calving represents a negative feed-back. The model proposed in the present study places more emphasis on ice flow in that the rate of retreat is dictated by the rate of thinning rather than the reverse.

With the presently available measurements on tidewater calving, it is not possible to decide unambiguously in favor of any one calving model. Neither the commonly used linear-calving relation (Equation (2)), or variations on it, nor the model proposed here, benefits from theoretical support. Despite the pioneering work of Hughes (1992), a complete theoretical description of tidewater calving
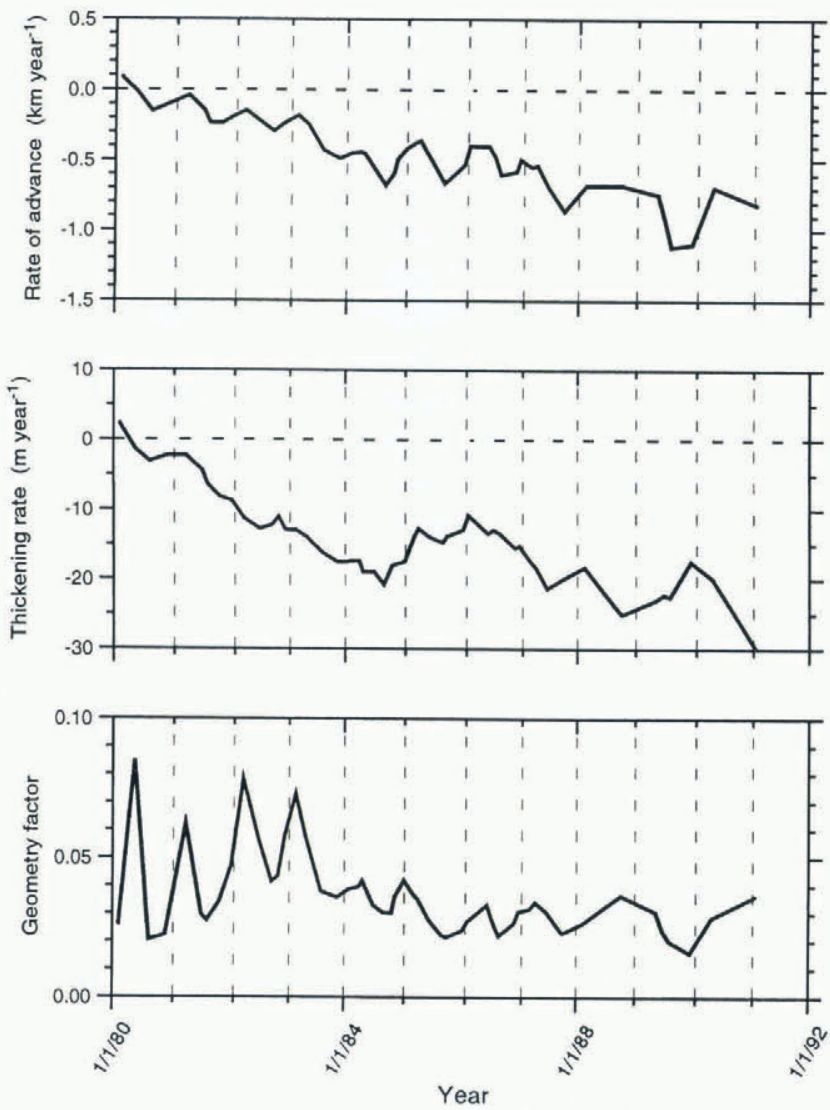

Fig. 9. 2 year running-mean values of the rate of terminus advance (negative for retreat), rate of thickness change (negative when thinning) and geometry factor. 
remains lacking. Whatever processes are to be included in any model, it is evident from the Columbia Glacier data that the retreat of this glacier cannot be understood without consideration of dynamical processes, such as ice speed and thinning of the terminal region.

\section{GONGLUSIONS}

Iceberg calving from grounded tidewater glaciers is a complex process that may be partially controlled by unpredictable local factors such as crevasse density (dictating where the ice is most likely to break off) or rainfall events (which may cause the ice to weaken as water enters the intraglacial drainage network). The random nature of these conditions limits our ability to predict short-term calving rates. However, it may be expected that these temporal fluctuations become less important when considering averages over 1 to several years, allowing the long-term calving rate to be estimated from a theoretical or empirical model. The usual approach has been to link the rate of calving to observable quantities, such as water depth or ice thickness at the calving front.

Available data on calving glaciers, suitable to test various models, can be divided into two categories. The first consists of glaciers that are in steady state or retreating at a slow rate. The main objection against the use of this data source is that derived correlations (for example, the linear relation between calving rate and water depth) may not be indicative of the causal process but, instead, reflect the adjustment of the glacier to its environment. A more appropriate category for testing calving models contains glaciers that are undergoing rapid change. At present, only one such glacier has been documented extensively, namely Columbia Glacier, Alaska, which has been monitored since the mid-1970s, well before the onset of drastic retreat.

Data collected on Columbia Glacier do not unambiguously support the commonly adopted linear-calving law (Equation (2)), or any other correlation between calving rate and measured quantities, other than perhaps the height above buoyancy. It could be argued that the uncertainty in especially the basal topography is sufficiently large to interpret these data as supportive of the linear-calving relation (as has been done by Meier (1994), on the basis of fewer data points), although this would require considerable adjustment to the basal elevations derived by Rasmussen (1989) and also used in this study. In particular, the data suggest that the increase in calving rate did not occur until after the terminus had retreated to the foot of the terminal moraine. According to the calving law (Equation (2)), the rate of calving should have increased sooner as the terminus started to retract from the moraine. If adopted, however, the conventional model for iceberg calving fails to explain other prominent features observed during the retreat of Columbia Glacier.

There are three observations that raise the question whether a calving relation actually exists. First, during the retreat, the speed of Columbia Glacier increased almost as much as did the calving rate, such that the two are linearly correlated. This is a surprising result, because basal sliding is generally believed to be controlled mainly by the effective basal pressure or by the amount of water present beneath the glacier. It is not clear how either of these would affect the production of icebergs and why the dependence of the calving rate on effective basal pressure or water storage would be similar in form to that of the sliding velocity. Secondly, calving is usually attributed to the unbalanced lithostatic stress at the glacier front. However, this stress decreased as Columbia Glacier retreated, yet the rate of calving increased by almost a factor of 7 . Thirdly, the rate of terminus retreat appears to be correlated with the rate of surface lowering in the glacier snout or, equivalently, to the thinning rate. None of these findings can be readily explained by the linearcalving relation or a more complicated extension.

A different mechanism for calving is proposed in this study, inspired by the suggestion of Meier and Post (1987) that the terminus appears to retreat to the point where the effective basal pressure approaches zero. The mechanism envisioned here is that the terminus retreats, if the thickness in excess of flotation becomes less than some critical value. For Columbia Glacier, the minimum thickness required for the terminus to remain steady is about $50 \mathrm{~m}$ above the (local) flotation thickness. According to this scenario, retreat is initiated when the terminal thickness becomes too small and the rate of retreat is controlled by the thinning rate and the basal slope. In this model, the calving rate is a secondary parameter, determined by the rate of retreat and ice velocity. Consequently, if the glacier speed increases, the calving rate increases proportionally, perhaps with a short time delay, to maintain the rate of terminus retreat.

In contrast to earlier calving models, the model proposed here is able to explain, at least in a qualitative sense, observations made on Columbia Glacier during its rapid retreat. Nevertheless, there is, at present, little theoretical support for this new mechanism and physical justification remains speculative. The ice in temperate tidewater glaciers is generally too weak to support a floating tongue. It may be that, as flotation is approached and basal drag reduced, the snout cannot maintain its integrity and disintegrates. However, the nature of the processes involved remains unclear.

If accepted, the present model dictates a re-evaluation of controls on the behavior of tidewater glaciers. It has been suggested that calving tidewater glaciers experience a cycle of slow advance, followed by a short period of rapid retreat or collapse, caused by increased calving rates as the terminus detaches from its terminal moraine and retreats into deeper water (Post, 1975; Meier and Post, 1987). Following this scenario, retreat can only be halted if the calving rate decreases again, usually after the terminus has retracted to the head of the fjord. According to the new calving model, however, retreat is initiated and maintained by thinning of the glacier. In the case of Columbia Glacier, continued thinning is most likely associated with the increase in glacier speed, and retreat may be expected to continue as long as these large speeds are maintained. The implication is that the behavior of tidewater glaciers is controlled more by processes acting at the glacier bed (for example, a sudden or gradual change in subglacial drainage or water storage; Kamb and others, 1994) than by what happens at the glacier terminus. 


\section{ACKNOWLEDGEMENTS}

Critical remarks and suggestions from M.F. Meier, T. Hughes and an anonymous referee are appreciated and helped improving the manuscript by identifying errors, misquotations and unclear formulations. R. M. Krimmel, from the U.S.G.S. (Tacoma), should be commended for his diligent efforts in continuing the aerial photogrammetry of Columbia Glacier, without which this study would not have been possible, and for making the data available in digital form. This work was made possible by financial support from the U.S. National Science Foundation through grant OPP-9321556. This is Byrd Polar Research Center contribution No. C-1000.

\section{REFERENCES}

Bindschadler, R. 1983. The importance of pressurized subglacial water in separation and sliding at the glacier bed. f. Glaciol., 29 (101), 3-19.

Broecker, W.S. 1994. Massive iceberg discharges as triggers for global climate change. Nature, 372 6505), 421-424.

Brown, C. S., M. F. Meier and A. Post. 1982. Calving speed of Alaska tidewater glaciers, with application to Columbia Glacier. U.S. Geol. Surv. Prof. Pap. 1258-C.

Brown, C. S., L. A. Rasmussen and M. F. Meier. 1986. Bed topography inferred from airborne radio-echo sounding of Columbia Glacier, Alaska. U.S. Geol. Surv. Prof. Pap. 1258-G.

Clarke, G.K.C. 1987. Fast glacier flow: ice streams, surging and tidewater glaciers. 7. Geophys. Res., 92(B9), 8835-8841.

Dickson, D. 1978. Glacier retreat threatens Alaskan oil tanker route. Nature, 273, $88-89$.

Echelmeyer, K., T.S. Clarke and W.D. Harrison. 1991. Surficial glaciology of Jakobshavns Isbræ, West Greenland: Part I. Surface morphology. J. Glaciol., 37 (127), 368-382.

Fountain, A. G. 1982. Columbia Glacier photogrammetric altitude and velocity: data set (1957-1981). U.S. Geol. Surv. Open File Rep. 82-756.

Heinrich, H. 1988. Origin and consequences of cyclic ice rafting in the northeast Atlantic Ocean during the past 130,000 years. Quat. Res., 29 2), $142-152$.

Hodge, S. M. 1974. Variations in the sliding of a temperate glacier. $f$. Glaciol., 13 (69), 349-369.

Hodge, S. M. 1979. Instability of a calving glacier terminus. [Abstract.] f. Glaciol., $24(90), 504$.

Holdsworth, G. 1978. Some mechanisms for the calving of icebergs. In Husseiny, A. A., ed. Iceberg utilization. New York, Pergamon Press, $160-175$.

Hooke, R. LeB., J. Brzozowski and C. Bronge. 1983. Seasonal variations in surface velocity, Storglaciären, Sweden. Geogr. Ann., 65A (3 4), 263-277.

Hughes, T. 1989. Calving ice walls. Ann. Glaciol., 12, 7480.

Hughes, T. 1992. Theoretical calving rates from glaciers along ice walls grounded in water of variable depths. J. Glaciol., 38(129), 282294.

Hughes, T. and M. Nakagawa. 1989. Bending shear: the ratecontrolling mechanism for calving ice walls. f. Glaciol., $35(120)$, $260-266$.

Iken, A., H. Röthlisberger, A. Flotron and W. Haeberli. 1983. The uplift of Unteraargletscher at the beginning of the melt season-a consequence of water storage at the bed? F. Glaciol., 29(101), 28-47.

Kamb, B., H. Engelhardt, M. A. Fahnestock, N. Humphrey, M. Meier and D. Stone. 1994. Mechanical and hydrologic basis for the rapid motion of a large tidewater glacier. 2. Interpretation. J. Geophys. Res., 99 B8), 15,231-15,244

Krimmel, R. M. 1987. Columbia Glacier, Alaska: photogrammetry data set 1981-82 and 1984-85. U.S. Geol. Surv. Open File Rep. 87-219.

Krimmel, R.M. 1992. Photogrammetric determinations of surface altitude, velocity, and calving rate of Columbia Glacier, Alaska, 1983-91. U.S. Geol. Surv. Open File Rep. 92-104.

Krimmel, R.M. and B.H. Vaughn. 1987. Columbia Glacier, Alaska: changes in velocity 1977-1986. J. Geophys. Res., 92(B9), 8961-8968.
Meier, M. F. 1979. Variations in time and space of the velocity of lower Columbia Glacier, Alaska. J. Glaciol., $23(89), 408$.

Meier, M. F. 1994. Columbia Glacier during rapid retreat: interactions between glacier flow and iceberg calving dynamics. In Reeh, N., ed. Report of a Workshop on "The Calving Rate of the West Greenland Glaciers in Response to Climate Change", Copenhagen, 13-15 September 1993. Copenhagen, Danish Polar Center, 63-83.

Meier, M. F. and A. Post. 1987. Fast tidewater glaciers. J. Geophys. Res., 92 (B9), 9051-9058.

Meier, M.F., L.A. Rasmussen and D.S. Miller. 1985a. Columbia Glacier in 1984: disintegration under way. U.S. Geol. Surv. Open Fïle Rep. 85-81.

Meier, M. F., L. A. Rasmussen, R. M. Krimmel, R. W. Olsen and D. Frank. 1985b. Photogrammetric determination of surface altitude, terminus position, and ice velocity of Columbia Glacier, Alaska. U.S. Geol. Surv. Prof. Pap. 1258-F.

Meier, M. and 9 others. 1994. Mechanical and hydrologic basis for the rapid motion of a large tidewater glacier. 1. Observations. J. Geophys. Res., 99 (B8), 15,219-15,229.

Paterson, W.S.B. 1994. The physics of glaciers. Third edition. Oxford, etc., Elsevier.

Pelto, M. S. and C. R. Warren. 1991. Relationship between tidewater glacier calving velocity and water depth at the calving front. Ann. Glaciol., 15, 115-118.

Pollard, D. 1984. Some ice age aspects of a calving ice sheet model. In Berger, A., J. Imbrie, J. Hays, G. Kukla and B. Saltzman, eds. Milankovitch and climate: understanding the response to astronomical forcing. Part 2. Dordrecht, etc., D. Reidel Publishing Co., 541-564. (NATO ASI Series C: Mathematical and Physical Sciences 126.)

Post, A. 1975. Preliminary hydrography and historic terminal changes of Columbia Glacier, Alaska. U.S. Geol. Surv. Hydrol. Invest. Atlas HA559. (3 maps, scale 1:10,000.)

Powell, R. D. 1991. Grounding-line systems as second-order controls on fluctuations of tidewater termini of temperate glaciers. In Anderson, J.B. and G.M. Ashley, eds. Glacial marine sedimentation; paleoclimatic significance. Boulder, CO, Geological Society of America, 75-93. (GSA Special Paper 261.)

Rasmussen, L.A. 1989. Surface velocity variations of the lower part of Columbia Glacier, Alaska, 1977-1981. U.S. Geol. Surv. Prof. Pap. 1258-H.

Rasmussen, L. A. and M. F. Meier. 1982. Continuity equation model of the predicted drastic retreat of Columbia Glacier, Alaska. U.S. Geol. Surv. Prof. Pap. 1258-A.

Reeh, N. 1968. On the calving of ice from floating glaciers and ice shelves. 7. Glaciol., 7 (50), 215-232.

Reeh, N. 1994. Calving from Greenland glaciers: observations, balance estimates of calving rates, calving laws. In Reeh, N., ed. Report of a Workshop on "The Calving Rate of the West Greenland Glaciers in Response to Climate Change", Copenhagen, 13-15 September 1993. Copenhagen, Danish Polar Center, 85-102.

Sikonia, W. G. 1982. Finite-element glacier dynamics model applicd to Columbia Glacier, Alaska. U.S. Geol. Surv. Prof. Pap. 1258-B.

Sikonia, W. G, and A. Post. 1980. Columbia Glacier, Alaska: recent ice loss and its relationship to seasonal terminal embayments, thinning and glacial flow. U.S. Geol. Surv. Hydrol. Invest. Atlas HA-619. (3 sheets.)

Tangborn, W. V., R. M. Krimmel and M. F. Meier. 1975. A comparison of glacier mass balance by glaciological, hydrological and mapping methods, South Cascade Glacier, Washington. International Association of Hydrological Sciences Publication 104 (Symposium at Moscow 1971 Snow and Ice), 185-196.

Thomas, R. H. 1977. Calving bay dynamics and ice sheet retreat up the St. Lawrence valley system. Géogr. Phys. Quat., 31(3-4), 347-356.

Van der Veen, C.J. 1995. Controls on calving rate and basal sliding: observations from Columbia Glacier, Alaska, prior to and during its rapid retreat, 1976-1993. Byrd Polar Research Center. Report 11.

Walters, R. A. and W. W. Dunlap. 1987. Analysis of time series of glacier speed: Columbia Glacier, Alaska. J. Geophys. Res., 92 B9), 8969 8975.

Warren, C. R. 1992. Iceberg calving and the glacioclimatic record. Prog. Phys. Geogr., 16 (3), 253-282.

Warren, C. R. and N. R.J. Hulton. 1990. Topographic and glaciological controls on Holocene ice-sheet margin dynamics, central West Greenland. Ann. Glaciol., 14, 307-310. 